\title{
The influences of admixtures on the characteristics of pore structure of low-temperature concrete under different curing conditions
}

\author{
Yue Tian ${ }^{1 *}$, Wanlai Zhang ${ }^{1}$ and Yihang Zhang ${ }^{2}$ \\ ${ }^{1}$ Civil Engineering Department, Shenyang Urban Construction University, Shenyang, Liaoning Province, 110167, China \\ ${ }^{2}$ Fuxin Thermal Housing Development Co., Ltd., Fuxin, Liaoning Province, 123000, China
}

\begin{abstract}
Based on the construction characteristics in the Northeast China Region under low temperature conditions, this article studies the influences of admixtures without antifreezing agent of different types and amounts on the low-temperature concrete and characteristics of pore structure. The results show that the amount of the admixtures is stable, the compressive strength of concrete under the curing condition of low temperature naturally varying is higher than the strength under the curing condition of constant low temperature while the porosity of the concrete under the curing condition of low temperature naturally varying is lower than the porosity under the curing condition of constant low temperature; The most appropriate curing method for the concrete used in winter construction is the curing method of low temperature naturally varying.
\end{abstract}

\section{Introduction}

Durability of concrete has become a research focus at home and abroad. The cold injury is the main problem of the durability of concrete in northern China. The cold injury of concrete at its early age causes irreparable damages to its durability in later period. Studying the characteristics of low-temperature concrete plays a significant role in protecting concrete from cold injury at its early age and improving the durability of lowtemperature concrete in later period. Traditionally, antifreezing agents are always used for concrete for winter construction. However, the antifreezing agent has many shortcomings, for example, the antifreezing agent with chlorides corrodes steel concrete reinforcing bars, the antifreezing agent with amides makes concrete produce ammonia gases which is harmful to health and so on. Fly ash and silica fume are both active mineral admixtures for concrete which can replace some cements in concrete. Its secondary hydration in later period can significantly improve the compressive strength and the durability such as the resistance to corrosion in later period. The writer adopts the concrete without antifreezeing agents, the characteristics of pore structure of concrete with fly ash and silica fume are tested by adjusting the addition amount and adding methods of fly ash and silica fume under the curing conditions of minus temperature naturally varying and constant minus temperature, and the development of pore structure can be verified through the tests on the compressive strength at different ages to determine the reasonable amount of admixtures and the appropriate curing methods for concrete for winter construction.

\section{Raw materials and experimental methods}

\subsection{Raw materials}

Portland cement(P.O 42.5)produced by Shenyang Jidong Cement Limited Company ; ordinary water ; coarse aggregate is gravel with the grain diameter of $5-20 \mathrm{~mm}$ and continuous grain gradation; fine aggregate is river sand with fineness modulus of 2.8 ; fly ash FA is the Ilevel coal ash produced by a thermal power plant in Shenyang; silica fume SF is the silica fume produced by Qinghai Huadian Ferroalloy Limited Liability Company; superplasticizer is $\mathrm{FN}-1$ and the early strength agent is $\mathrm{Na}_{2} \mathrm{SO}_{4}$

\subsection{Experimental methods}

\subsubsection{Concrete composition}

Table 1.Mix proportion of concrete

\begin{tabular}{cccccc}
\hline \multicolumn{5}{c}{ Weight of All Materials in $1 \mathrm{~m}^{3}$ Concrete $(\mathrm{kg})$} \\
\hline Water/B & Water & Cement & Sand & Sand & Gravel \\
inder & 170 & 378 & $35 \%$ & 649 & 1202 \\
0.45 & Ratio &
\end{tabular}

The amount of the extra admixture is mixed. The admixture can be made by adjust the amounts of the fly ash and the silica fume. 
Table2.The amount of the additives and mineral admixtures (\%)

\begin{tabular}{ccccc}
\hline \multirow{2}{*}{ specimen } & $\begin{array}{c}\text { Amount of Early } \\
\text { Strength Agent }\end{array}$ & $\begin{array}{c}\text { Amount of } \\
\text { superplasticizer }\end{array}$ & $\begin{array}{c}\text { Amount of Fly } \\
\text { Ash }\end{array}$ & Amount of Silica Fume \\
\hline A & 0.05 & 1 & - & - \\
B & 0.05 & 1 & 10 & - \\
C & 0.05 & 1 & 15 & - \\
D & 0.05 & 1 & 20 & - \\
E & 0.05 & 1 & - & 5 \\
F & 0.05 & 1 & - & 8 \\
G & 0.05 & 1 & - & 10 \\
H & 0.05 & 1 & 15 & 5 \\
\hline
\end{tabular}

\subsubsection{Curing condition}

(1)Curing condition of the outdoor low temperature naturally varying: early winter and early spring can be chosen and the variation range of curing temperature is from $-15^{\circ} \mathrm{C}$ to $5^{\circ} \mathrm{C}$.

(2) Curing condition of constant low temperature in refrigerator: adjust the temperature of the refrigerator to the constant temperature of $-10 \pm 1^{\circ} \mathrm{C}$ for curing.

\subsubsection{Strength measurement}

Measure the concrete strength development with mineral admixtures of different amounts and adding ways at respective low-temperature curing periods of $1 \mathrm{~d}, 3 \mathrm{~d}, 7 \mathrm{~d}$, $-7 \mathrm{~d}+7 \mathrm{~d},-7 \mathrm{~d}+28 \mathrm{~d}$.

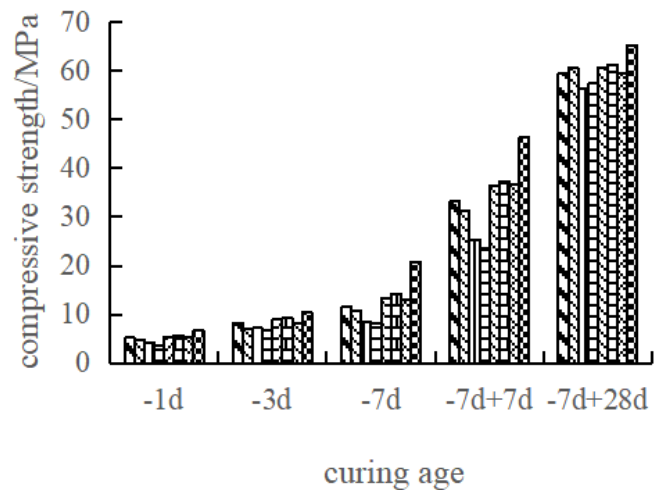

(a)

\subsubsection{Porosity measurement}

The porosity of concrete can be obtained indirectly by testing the loss percentage of water content of a saturated test specimen on the certain condition. This method is called "vaporizable water content method".

\section{Experimental result and analysis}

\subsection{Influences by admixtures on concrete strength under different curing conditions}

\subsubsection{Influences by admixture on concrete strength under curing condition of constant low temperature}

Figure1 (a) shows the compressive strength of the concrete with different admixtures at different ages under the condition of constant low temperature.

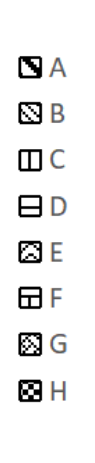

Figure 1. Influences by admixtures on the compressive strength of concrete under different conditions

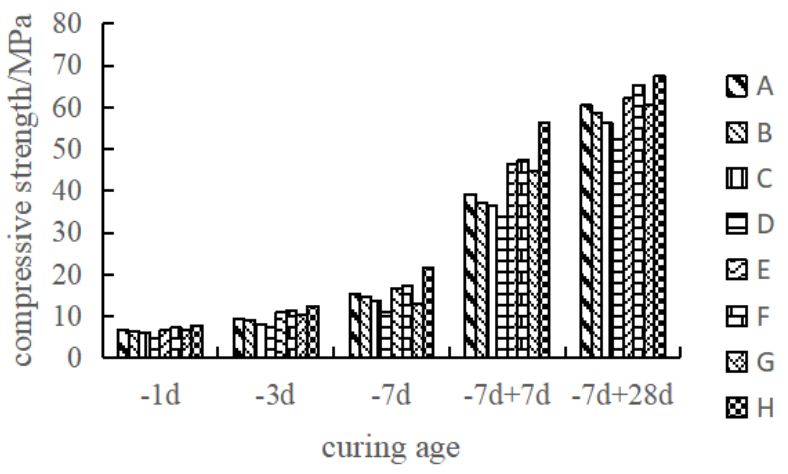

(b)
It can be seen from figure 1(a) that the compressive strength of the concrete with admixtures is similar to the the compressive strength of the concrete without admixtures. The strength of concrete decreases gradually with the increase of fly ash content, especially when the fly ash content exceeds $15 \%$. It can be seen from the figure 1(a) that the compressive strength of the concrete cured for 28 days is similar to or even stronger than the strength of the concrete without fly ash. Because the fly ash particles are dispersed in the cement paste and a layer of relatively solid hydrated gel which is closely combined with the paste is thus formed on the surface of micro glass beads. Therefore, the compressive strength of the concrete with fly ash increases rapidly in the middle and later periods. When the silica fume content is fixed between $5 \%$ to $10 \%$, the strength of concrete increases firstly and then decreases gradually as the content increases. Therefore, the content of silica fume should not exceed $8 \%$. However, the compressive strength of the concrete with silica fume is generally higher than the strength of concrete without silica fume. When the concrete is added with both fly ash and silica 
fume, its compressive strength generally becomes stronger at different ages. Due to the effect of tight filling, when the admixture content is appropriate, the internal pore structure is improved, channels for macro pores are obstructed and the amount of water which can be frozen is reduced, so that the compressive strength of the concrete is continuously developed under the low temperature.

\subsubsection{Influences by admixture on concrete strength under curing condition of low temperature naturally varying}

Figure1(b) shows the development of the compressive strength of the concrete with different admixtures under the curing condition of the low temperature naturally varying of $-15^{\circ} \mathrm{C} \sim 5^{\circ} \mathrm{C}$.

It can be seen from Figure1(b) that the development of the influences by different admixtures on the strength of concrete under the curing condition of low temperature naturally varying are consistent with the influences on the strength of the concrete under the curing condition of constant low temperature. However, the compressive strength of the concrete under the curing

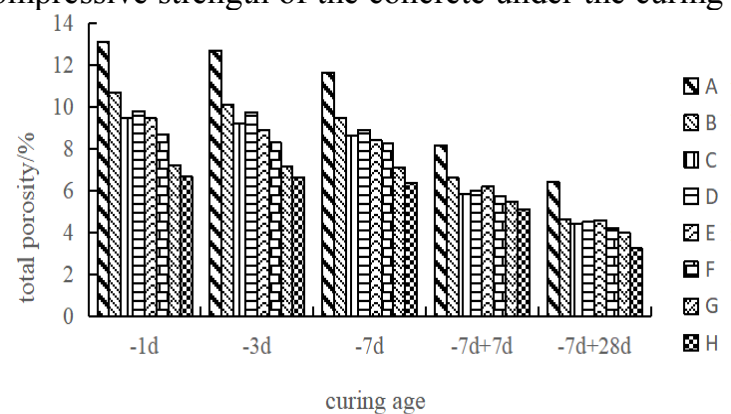

(a) condition of low temperature naturally varying is stronger than the the strength of the concrete under the curing condition of constant low temperature. Since the internal structure of concrete has been damaged and the compressive strength of the concrete has been lost when the concrete is always cured under constant low temperature. However, under the curing condition of low temperature naturally varying, the natural temperature change enables the concrete to experience the freezing and thawing cycle, which can make the concrete easier to be hydrated.

\subsection{Influences by admixtures on concrete porosity under different curing conditions}

\subsubsection{Influences by admixtures on concrete porosity under the curing condition of constant low temperature}

The influences by fly ash and silica fume of different amounts on the concrete porosity are measured. It can be shown in Figure 2(a)(b)(c).

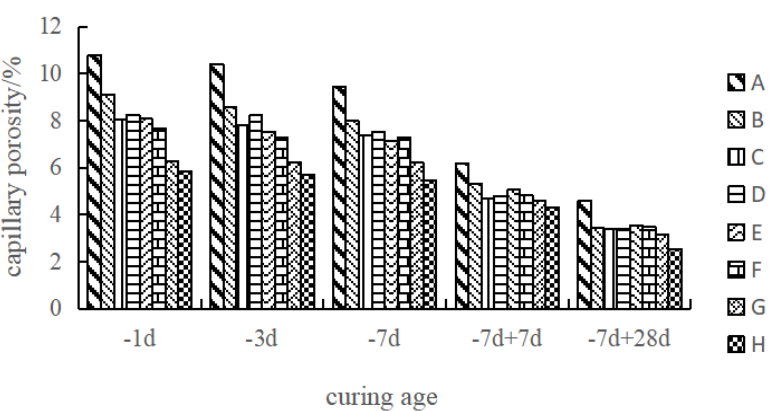

(b)

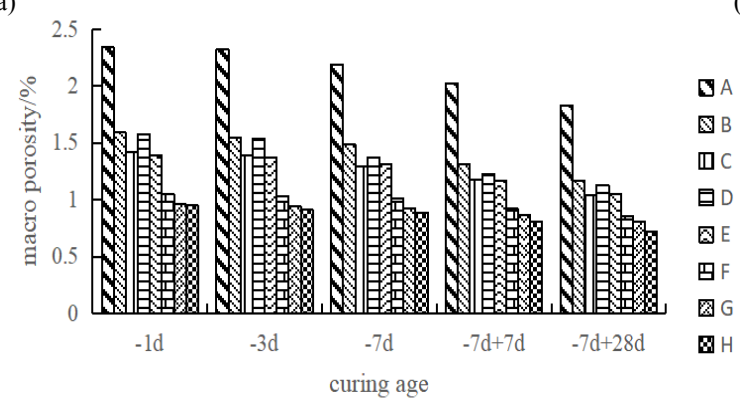

(c)

Figure2.Influences by contents of admixtures on concrete corosity under constant low temperature

It is can be seen from the Figure 2 that: adding the admixtures largely decreases the concrete porosity. As the fly ash and silica fume further increases, the total porosity and the capillary porosity gradually decreases. However, that with the increase of fly ash, the strength of the concrete does not become higher with the decrease of the porosity of the concrete and the compactibility of the concrete. On the contrary, it is lower, especially when the fly ash content accounts for $15 \%$, the strength is seriously lowered. Consequently, it denies that the concrete is more compact and its compressive strength is stronger when the porosity is lower. The possible reason is that the compactibility of the concrete prevents it from better hydration. As a result, under the curing condition of constant low temperature, the fly ash content had better not account for $15 \%$ in the concrete. The compressive strength of the concrete with silica fume is stronger than the compressive strength of the concrete without silica fume. However, when the silica fume content exceeds $8 \%$, the compressive strength starts to be weaker. So the silica fume content is no more than $8 \%$, its compressive strength and microstructure is the best. The porosity of the concrete with both fly ash and silica fume is smaller than the concrete with fly ash only or silica fume only and the capillary pore structure of the concrete with both fly ash and silica fume is further improved. It shows that the fly ash and silica fume replacing some cements can complement each others 
advantages. From figure1, the compressive strength of concrete with fly ash accounting for $15 \%$ and silica fume accounting for $5 \%$ gradually increases with the increase of curing age, which means as long as only the proper amount of admixtures is added in the concrete, the porosity decreases and the compressive strength increases.

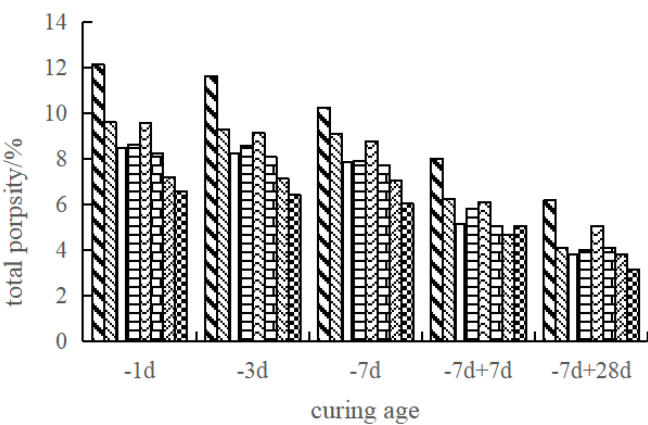

(a)

\subsubsection{Influences by admixtures on concrete porosity under the curing condition of low temperature naturally varying}

The influences exerted by the concrete with fly ash and silica fume of different amounts on concrete porosity are measured. Figure3 (a)(b)(c) shows the results.

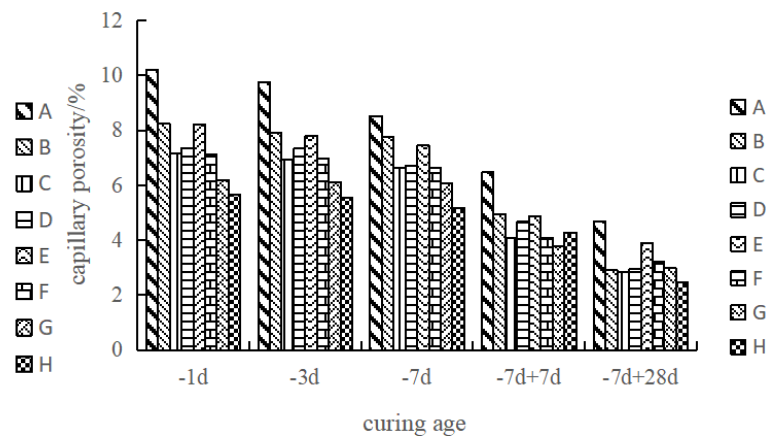

(b)

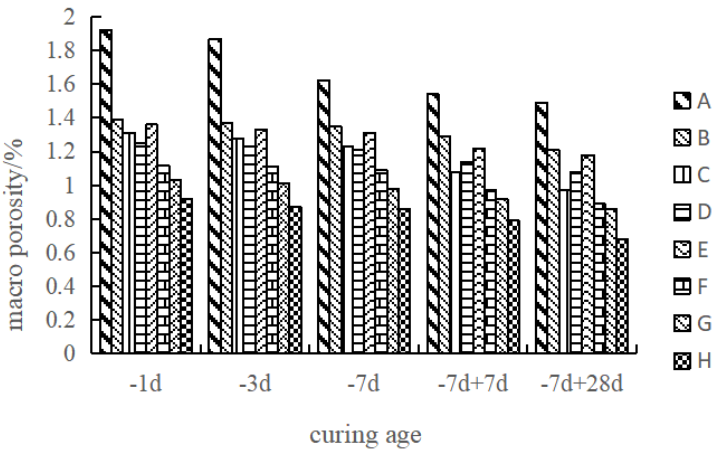

(c)

Figure3.Influences by admixtures on concrete porosity under low temperature naturally varying

It can be seen from the Figure 3 that, adding fly ash only and adding silica fume only have the same development about the influences on the concrete porosity under the constant low temperature of $-10^{\circ} \mathrm{C}$. However, the total porosity, capillary porosity and macro porosity of the concrete under the curing condition of the low temperature naturally varying is smaller than that of the concrete under the curing condition of constant low temperature. And the compressive strength of the concrete under the low temperature naturally varying is stronger than that of the concrete under the curing condition of constant low temperature. Since the concrete experiences a freezing and thawing cycle under the curing condition of constant low temperature, which makes the internal structure of concrete have been damaged and the compressive strength of the concrete

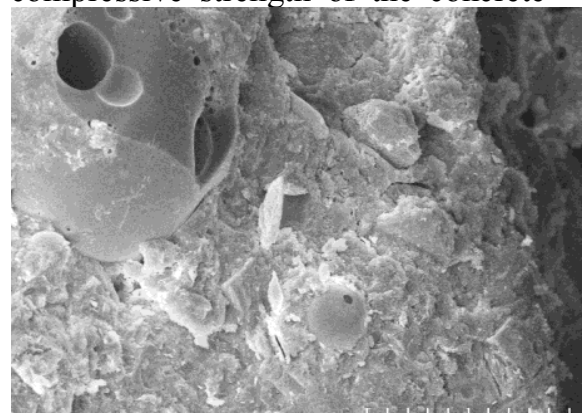

(a) specimen $\mathrm{A}$ have been lost. Therefore, it can be seen from both macro and micro aspects that concrete is more suitable for curing under low temperature conditions during winter construction. From both macroscopic and microscopic perspectives, the concrete for winter construction is more appropriate to be cured under the curing condition of low temperature naturally varying.

\subsection{Influences by admixtures on the micro structure of hydration products of concrete}

Morphology features of specimens cured at $-15^{\circ} \mathrm{C}-5^{\circ} \mathrm{C}$ for 7 days can be seen from Figure4.

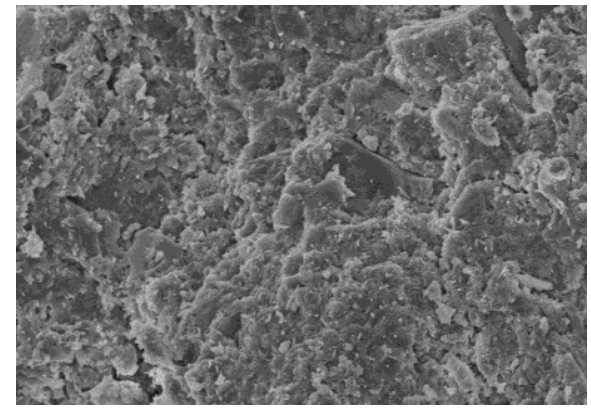

(b) specimen $\mathrm{H}$

Figure4. Microcosmic SEM diagram of concrete specimens cured at 7 days of age at $-15^{\circ} \mathrm{C}-5^{\circ} \mathrm{C}$ 
The figure shows that under the low temperature, the hydration degree of concrete with admixtures is generally lowered. Unhydrated admixtures particles are clearly found in specimens and many needlelike ettringites and $\mathrm{CH}$ crystals with a loose structure and large pores are clearly observed. For one thing, due to insufficient hydration, the joints between various structures are chaotic and irregular and the adhesion is poor which leaves the set cement matrix with many pores and results in a loose structure and reduced strength. For another, under low temperature, the cement hydrates slowly. The hydrated products have not completely wrapped the admixtures particles with larger diameter, so many admixtures particles can be seen. Moreover, under the minus temperature, admixtures particles with larger diameter have relatively weak activity. They mainly playing a role in filling. And the situation is improved as the particle diameter of the admixtures decreases.

\section{Conclusion}

(1)With the increasing of fly ash content, the strength of concrete decreases gradually at low temperature, especially when the fly ash content is more than $15 \%$. With the increasing of silica fume content, the compressive strength of concrete first increases and then decreases, so the content of fly ash should not exceed $15 \%$ and silica fume should not exceed $8 \%$. When the content of fly ash is $15 \%$ and silica fume is $5 \%$, the strength of concrete will increase by $28.8 \%$ compared with that of concrete without admixture, and the strength of concrete will continue to increase with the increasing of curing time.

(2) When the content of fly ash accounts for $10 \%$ $20 \%$, the porosity of low-temperature concrete increases firstly and then increases with the increase of fly ash content, but the strength gradually decreases; when the silica fume content account for $5 \%-10 \%$, as the silica fume increases, the porosity of the low-temperature concrete decreases but the strength increases firstly and then decreases. It is uncertain that the compressive strength is stronger when the porosity of the lowtemperature concrete with admixtures is lower. As a result, under the low temperature conditions, the fly ash content should account for no more than $15 \%$ and the silica fume content should account for no more than $8 \%$.

(3) Compared with the concrete under the curing condition of constant low temperature, the concrete under the curing condition of low temperature naturally varying has stronger comperssive strength and lower porosity. Consequently, the concretes for winter construction are more appropriate to be cured under the condition of outdoor low temperature naturally varying.

\section{Reference}

1. LIU, R.Q., LIU, Y., OU, Y. (2012) Study on internal structure formation of low-temperature concrete in early hydration. Concrete, 12:21-23.

2. HAO, C.W., DONG, M., MO, L.W., LIU, K.W. (2011) Surface modification of fly ash and its effect on strength and autogenous shrinkage of cement pastes. Journal of the Chinese cement society,39(4):698-702.

3. KURODA, M., WATANABE.T., NARIAKI, T. (2000) Increase of bond strength at interfacial transition zone by the use of fly ash. Cem Concr Res, 2000, 30(2): 253-258.

4. LIU, J., QI, H., LIU, R.Q. (2009) Influence of curing temperature on the frost-resisitance of lowtemperature concrete without antifreeze. Journal of Wuhan university of technology,31(7):49-51

5. Fuminori.T., Kwangryul. H. (2000) A study on the concrete using fly ash as a part of fine aggregate $[\mathrm{J}]$. Summaries of Technical Papers of Annual Meeting, 3:253-261.

6. Kwangryul.H, Fuminori.T. (2001) A properties of pore structure on the concrete using fly ash as a partial replacement for fine aggregate. Cement Science and Concrete Technology Japan Cement Association, 52: 86-87.

7. ZHANG, G., LI, G. (2016) Effects of mineral admixtures and additional gypsum on the expansion performance of sulphoaluminate expansive agent at simulation of mass concrete environment. Construction and Building Materials, 113: 970-978. 